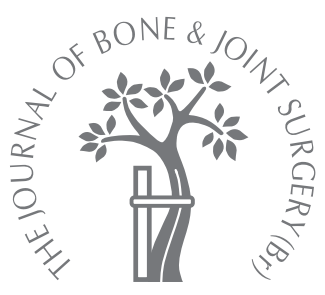

K.-J. Song, J. S. Johnson, B.-R. Choi, J. C. Wang, K.-B. Lee

From Department of Orthopaedic Surgery, Research Institute of Clinical Medicine, Chonbuk National University Medical School, Jeonju, South Korea

\title{
Anterior fusion alone compared with combined anterior and posterior fusion for the treatment of degenerative cervical kyphosis
}

\begin{abstract}
We evaluated the efficacy of anterior fusion alone compared with combined anterior and posterior fusion for the treatment of degenerative cervical kyphosis. Anterior fusion alone was undertaken in 15 patients (group A) and combined anterior and posterior fusion was carried out in a further 15 (group B). The degree and maintenance of the angle of correction, the incidence of graft subsidence, degeneration at adjacent levels and the rate of fusion were assessed radiologically and clinically and the rate of complications recorded. The mean angle of correction in group $B$ was significantly higher than in group $A(p=0.0009)$. The mean visual analogue scale and the neck disability index in group $B$ was better than in group $A(p=0.043,0.0006)$. The mean operation time and the blood loss in $B$ were greater than in group $A(p<0.0001,0.037)$. Pseudarthrosis, subsidence of the cage, and problems related to the hardware were more prevalent in group $A$ than in group $B(p=0.034,0.025$, 0.013).

Although the combined procedure resulted in a longer operating time and greater blood loss than with anterior fusion alone, our results suggest that for the treatment of degenerative cervical kyphosis the combined approach leads to better maintenance of sagittal alignment, a higher rate of fusion, a lower incidence of complications and a better clinical outcome.
\end{abstract}

A kyphotic deformity of the cervical spine may be iatrogenic following surgery. ${ }^{1}$ It may also be secondary to degenerative disease, trauma, neoplasia, or inflammatory arthritis, such as ankylosing spondylitis and rheumatoid disease. $^{2,3}$ There are no well-defined indications for the correction of such deformities, but surgical correction is considered in patients with severe posterior neck pain and a neurological deficit, in those with severe functional disabilities such as difficulty in swallowing, respiratory distress or a chin-chest deformity, and in progressive deformity. The best surgical approach remains a matter for debate. It may be anterior alone, posterior alone or a combined approach. The method used is determined by the flexibility of the deformity and the presence or absence of facet ankylosis. ${ }^{4-6}$

There are few papers evaluating the surgical treatment of this deformity and the majority focus on the surgical correction of post-laminectomy kyphosis ${ }^{1,2,7,8}$ or a fixed-type kyphosis. ${ }^{4,5}$ The characteristics of degenerative cervical kyphotic deformities differ from those due to other causes. The degenerative deformity progresses more slowly, the degree is generally not as severe, and it tends to be flexible. ${ }^{9}$ However, in our experience it can also lead to severe deformity, variable flexibility and neurological deficit. Therefore, it is important to determine which surgical approach leads to the best outcome.

Various studies have addressed the use of anterior approaches for decompression and reduction of this deformity. ${ }^{7,8,10}$ The anterior approach has advantages over the posterior in that it allows the direct removal of anterior compressive lesions via discectomy and/or corpectomy, and enables an anterior release by osteotomy for correction of the deformity. ${ }^{6,7,10,11}$ However, many studies have shown that the anterior approach has a high rate of complications such as pseudarthrosis and subsidence and dislodgement of the graft with multi-segmental constructs. ${ }^{11-13}$

The aim of this study was to evaluate the efficacy of a combined anterior and posterior fusion compared to anterior fusion alone in the treatment of degenerative cervical kyphotic deformity, based on the radiological and clinical outcome.

\section{Patients and Methods}

We retrospectively reviewed 37 patients with cervical kyphotic deformity who underwent
Received 8 April 2010; Accepted

after revision 13 July 2010 
Table I. Demographics of the study

\begin{tabular}{llcr}
\hline & Group A & Group B & p-value \\
\hline Number of patients & 15 & 15 & \\
Male:female & $6: 9$ & $9: 6$ & 0.2043 \\
Age in years (range) & 52.53 (34 to 77) & 58.80 (45 to 77) & 0.0769 \\
Follow-up in months (range) & $38.6 \quad$ (26 to 79) & $42.2 \quad$ (26 to 79) & 0.5377 \\
Myelopathy:radiculopathy & $3: 12$ & $6: 9$ & 0.1501 \\
Flexible:fixed & $12: 3$ & $9: 6$ & 0.2467 \\
Mean kyphotic angle ( ${ }^{\circ} ;$ range) & 7.53 (2 to 16) & 12.07 (2 to 28) & 0.2778 \\
Mean fusion level (range) & 2.05 (1 to 3) & $3.60 \quad$ (3 to 5) & $<0.0001$ \\
\hline
\end{tabular}

anterior fusion alone or a combined anterior and posterior fusion between March 2001 and March 2007. There were five patients with kyphosis due to causes other than degenerative, two with tumours and three following surgery, and two with less than two years of follow-up. These were excluded from the study, leaving 30 patients for assessment. The indications for operation included severe posterior neck pain which had not responded to conservative treatment after six months, and a neurological deficit resulting in radiculopathy and/or myelopathy.

The patients were divided into two groups. Group A comprised 15 who had an anterior fusion alone, and group B included 15 who had a combined anterior and posterior fusion. The details of the patients are shown in Table I.

All patients underwent pre-operative flexion-extension radiography of the cervical spine to determine the flexibility of the deformity. The deformities were divided into flexible or fixed, based on postural correction and the degree of correction of the angle. The flexible type was defined as posturally reducible beyond neutral on lateral extension radiographs, whereas the fixed type was not. ${ }^{14}$ There were 21 flexible deformities, 12 in group A and nine in group B, and nine fixed, three in group $A$ and six in group B. Traction using Gardner-Well calipers ( $5 \mathrm{lb}$ to $10 \mathrm{lb}$ ) was given for two or three days before operation in two patients with fixed deformities. All patients had intra-operative traction $(5 \mathrm{lb}$ to $10 \mathrm{lb}$ ) while being monitored with somatosensory evoked potentials. MRI of the cervical spine was undertaken before operation in all patients, and myelo-CT in the presence of cervical spinal stenosis or myelopathy.

Operative details. In an anterior fusion alone we employed the Smith-Robinson left anterior approach to gain access to the cervical spine. We used the PEEK cage (polyetheretherketone, Solis cage, Stryker, Hopkinton, Massachusetts) filled with iliac cancellous bone graft, and an anterior cervical plate (CSLP, Cervical Spine Locking Plate, AO Synthes, Duebendorf, Switzerland) in the combined anterior and posterior fusion (Fig. 1). Traction using GardnerWell calipers was used during the operation to reduce the deformity in the prone position, after which posterior fixation and fusion was performed using lateral mass plate and screws in six cases and polyaxial cervical lateral mass screw-rod in nine. The posterior fusion was performed using autogenous iliac cancellous bone and a local graft from the spinous process. The patient was then placed supine for anterior decompression and release, with fixation using a plate and cage filled with iliac cancellous bone. After operation all patients in both groups were immobilised with a Philadelphia brace for four weeks, and a soft collar for two further weeks.

Radiological and clinical assessment was performed immediately after operation and after six weeks, three, six and nine months, one year and two years. The cervical Cobb angle was measured as the angle formed by a line projected parallel to the posterior surface of the most cranial vertebral body, and a line parallel to the posterior surface of the most cranial vertebral body within the deformity. Lordosis was defined as a negative and kyphosis as a positive angle. ${ }^{15}$ Postoperative fusion was assessed on dynamic radiographs reviewed by independent musculoskeletal radiologists using the criteria established by Steinmetz et al. ${ }^{6}$ In questionable cases, CT scans were used as a secondary measure when bridging trabeculae were not observed or their presence was uncertain on plain radiographs. Cage subsidence was defined as $>3 \mathrm{~mm}$ between the mid-point of the upper margin of the upper and the lower margin of the lower vertebral body. Adjacent level degenerative changes were assessed using the modified Hilibrand criteria ${ }^{16}$ and were divided into four stages, depending on the presence of a decrease in disc height and posterior osteophyte formation. In stage I there was no difference between the pre- and post-operative radiographs; stage II showed a decrease in disc height $<50 \%$ with no formation of posterior osteophytes; stage III had formation of posterior osteophytes with a decrease in disc height $<50 \%$; and stage IV a decrease in disc height $>50 \%$. We considered stage III and IV to be adjacent level degeneration.

We analysed the length of the operation and the blood loss. The post-operative complications were evaluated from the medical records and included the rate of pseudarthrosis, the need for revision surgery, the incidence of cage subsidence and adjacent level degeneration, complications related to the implants, dysphagia and infection. Clinical outcomes were assessed by a ten-point visual analogue scale (VAS) evaluating pain in the neck and arm and by the neck disability index. ${ }^{17}$

Statistical analysis. The chi-squared test was used for statistical comparison of each group prior to surgery, and for 


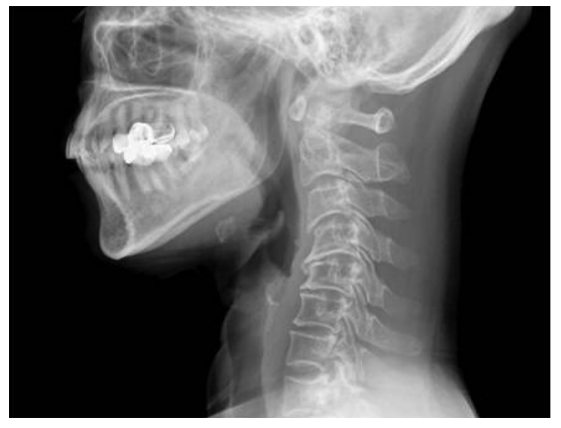

Fig. 1a

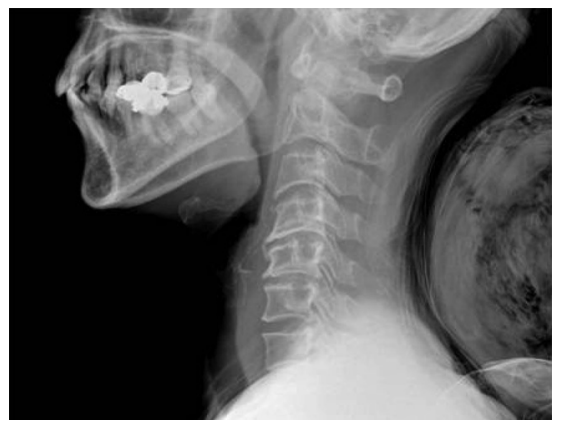

Fig. 1b

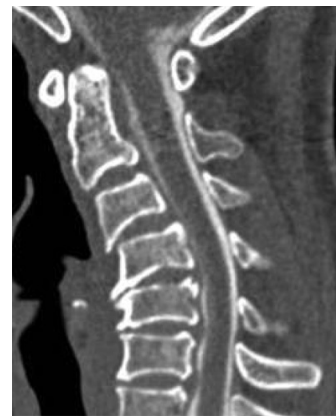

Fig. 1c

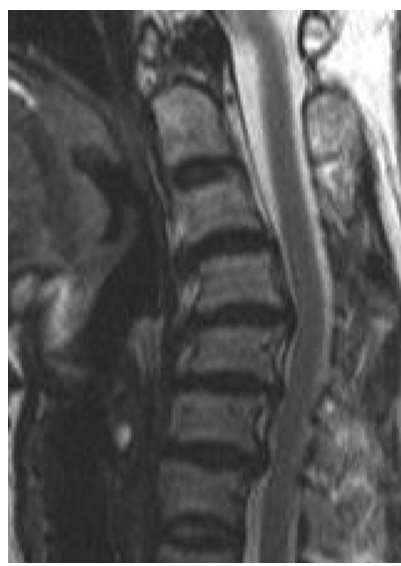

Fig. 1d

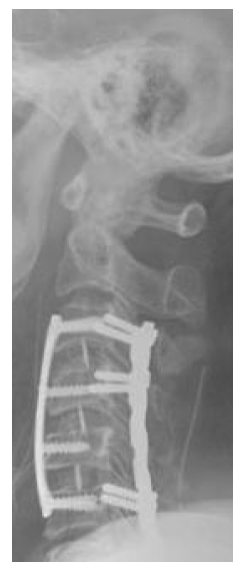

Fig. 1e

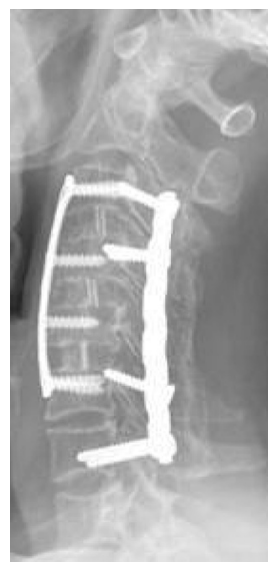

Fig. $1 f$

Lateral radiographs of the cervical spine showing a) a fixed degenerative cervical kyphotic deformity, b) after pre-operative traction showing correction of the kyphotic deformity. Figure 1c - a sagittal myelo-CT image and d) T2-weighted MR image showing compression of the cord by the deformity and multiple disc degeneration at C3-6. Figure 1e-post-operative radiograph showing combined anterior and posterior fusion and correction of the deformity and f) at the last follow-up, fusion and the maintenance of sagittal alignment.

Table II. The change of correction angle during follow-up

\begin{tabular}{lcccc}
\hline & Pre-operative $\left({ }^{\circ}\right.$; range $)$ & Post-operative $\left({ }^{\circ}\right.$; range $)$ & Mean change $\left({ }^{\circ}\right.$; range) & Last follow-up $\left({ }^{\circ}\right.$; range $)$ \\
\hline Group A & $5.53(2$ to 16$)$ & $-7.47(-20$ to 11$)$ & $13.00(2$ to 29$)$ & $-3.87(-16$ to 11$)$ \\
Group B & $12.07(2$ to 28$)$ & $-12.0(-26$ to 0$)$ & $24.67(9$ to 42$)$ & $-10.20(-26$ to 3$)$ \\
p-value & & & 0.0009 & 0.0428 \\
\hline
\end{tabular}

comparison of complication rates between groups. The radiological and clinical results were compared using an independent $t$-test. All statistical analyses were performed using SPSS (version 15, SPSS Inc., Chicago, Illinois), and statistical significance was defined as $\mathrm{p}<0.05$.

\section{Results}

Radiological. The mean changes in the angles of correction in the two groups immediately post-operatively and at final follow-up are shown in Table II. The mean angle of correction immediately post-operatively was significantly better in group $B$ than in group A ( $\mathrm{p}=0.0009)$. This was also true at final follow-up, but with less significant statistical difference ( $\mathrm{p}=0.0428)$. There was some loss of correction in both groups. A recurrent kyphotic deformity was seen in four of $15(27 \%)$ in group $A$ and in none in group B.

Clinical outcomes. The mean operating time was $86.27 \mathrm{~min}$ utes (63 to 130 ) in group A, and 266.4 minutes (205 to 367 ) in group B. The mean blood loss was $188.2 \mathrm{ml}$ (80 to 300) in group A, and $329.33 \mathrm{ml}$ (140 to 490) in group B.

The improvements in the clinical outcome in the two groups at final follow-up are shown in Table III and Figure 2. The improvements in pain and the neck disability index were significantly better in group B than in group A $(\mathrm{p}=0.0461, \mathrm{p}=0.0360)$. 
Table III. The improvement of the visual analogue scale and neck disability index between the groups

\begin{tabular}{|c|c|c|c|c|c|c|}
\hline & \multicolumn{3}{|c|}{ Visual analogue scale } & \multicolumn{3}{|c|}{ Neck disability index } \\
\hline & $\begin{array}{l}\text { Pre-operative } \\
\text { (range) }\end{array}$ & $\begin{array}{l}\text { Last follow-up } \\
\text { (range) }\end{array}$ & $\begin{array}{l}\text { Improvement } \\
\text { (range) }\end{array}$ & $\begin{array}{l}\text { Pre-operative } \\
\text { (range) }\end{array}$ & $\begin{array}{l}\text { Last follow-up } \\
\text { (range) }\end{array}$ & $\begin{array}{l}\text { Improvement } \\
\text { (range) }\end{array}$ \\
\hline Group A & 6.47 (3 to 8 ) & 3.67 (0 to 7$)$ & 2.80 (0 to 6$)$ & 22.8 (18 to 30$)$ & $15.60(0$ to 15$)$ & 7.21 (0 to 28$)$ \\
\hline Group B & 7.67 (6 to 10$)$ & $1.80(0$ to 4$)$ & 5.87 (3 to 8 ) & 29.90 (22 to 41$)$ & $10.32(5$ to 18$)$ & 19.58 (9 to 26$)$ \\
\hline p-value & 0.0246 & 0.8303 & 0.0461 & 0.0256 & 0.7990 & 0.0360 \\
\hline
\end{tabular}

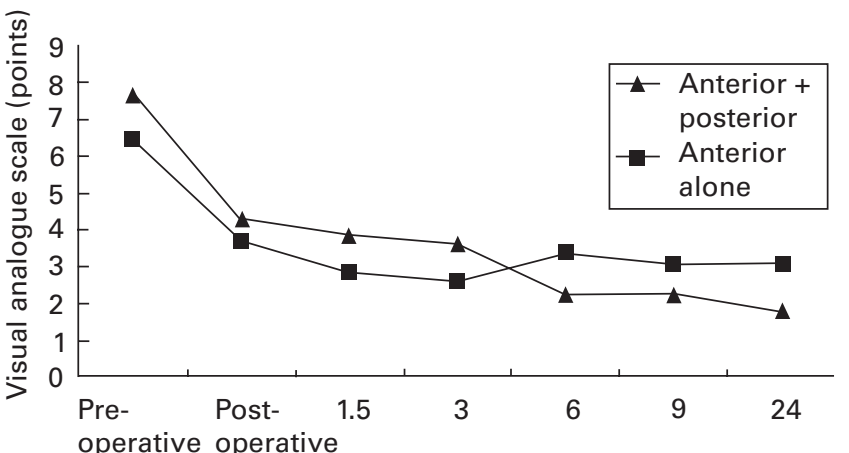

Evaluating time (mths)

Fig. 2a

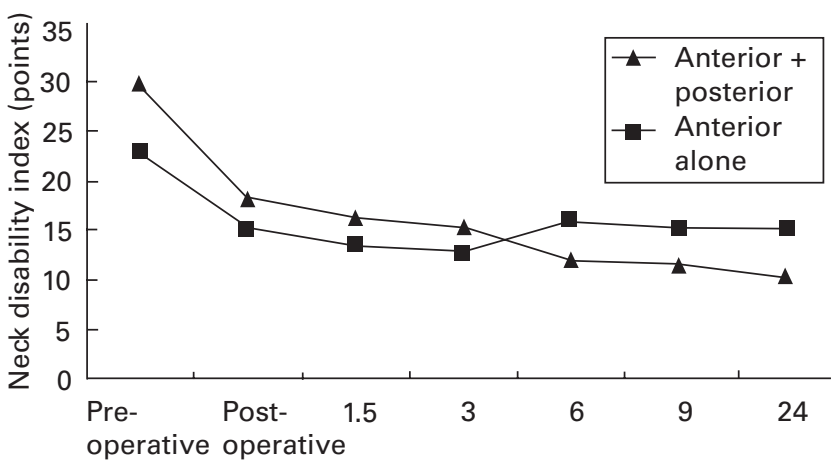

Evaluating time (mths)

Fig. $2 b$

The visual analogue scale a) and the neck disability index b) of both groups showing the decrease over time compared to the pre-operative status.

Complications. The complications in both groups are shown in Table IV. Pseudarthrosis developed in three patients $(20.0 \%)$ in group A but in none of group B. Subsidence of the cage occurred in six patients $(40 \%)$ in group A and one $(6.7 \%)$ in group B $(p=0.025)$.

Adjacent level degeneration occurred in four patients $(26.7 \%)$ in group A and in three $(20.0 \%)$ in group B; this was not statistically significant $(\mathrm{p}=0.666)$. Symptomatic disease at an adjacent level occurred in two patients $(13.3 \%)$ in group A and none in group B.

A revision procedure was performed on two patients in group A but on none in group B. Of the two revisions, one was laminoplasty and anterior decompression and fusion
Table IV. Complications

\begin{tabular}{llll}
\hline & \multicolumn{2}{c}{$\begin{array}{l}\text { Group A } \\
(\mathbf{n}=\mathbf{1 5})\end{array}$} & $\begin{array}{l}\text { Group B } \\
(\mathbf{n}=15)\end{array}$ \\
\hline Pseudarthrosis & $\mathbf{p}$-value \\
Revision surgery & $3(20.0)$ & $0(0.0)$ & 0.034 \\
Hardware-related complications & $2(13.3)$ & $0(0.0)$ & 0.088 \\
Dysphagia & $3(26.7)$ & $0(0.0)$ & 0.013 \\
Infection & $0(0.0)$ & $2(13.3)$ & 0.623 \\
Cage subsidence & $6(40.0)$ & $1(6.7)$ & - \\
Adjacent level degeneration & $4(26.7)$ & $3(20.0)$ & 0.025 \\
\hline
\end{tabular}

for adjacent level disease, and the other was a combined anterior and posterior fusion due to loss of correction of the kyphosis.

Complications related to the implants, such as displacement of a screw or bending of a plate, occurred in four patients in group A and none in group B. In the four patients in group A pseudarthrosis developed in one patient, but revision surgery was not required because there were no symptoms. The other three showed evidence of fusion on subsequent visits.

Dysphagia lasting for more than six weeks occurred in three patients in group A and in two in group B. All resolved within six months. There were no cases of donor site infection or of pain persisting for more than one month.

\section{Discussion}

Degenerative cervical disease is the most common cause of kyphosis seen in old age. 9 The focus of most previous studies $^{17-19}$ of the surgical treatment of cervical spondylotic myelopathy with kyphosis has been the neurological recovery or rate of fusion after operation, rather than the quality of correction of the deformity or the surgical approach. The magnitude of kyphosis seen in degenerative disease is generally less severe than that seen as a complication of cervical laminectomy, and the clinical manifestation is chiefly a myelopathy rather than the functional disability caused by the deformity. ${ }^{9}$ Some studies have evaluated the surgical treatment for cervical kyphosis due to other causes, such as after laminectomy, tumour and trauma. ${ }^{1-8}$ In this study, the kyphotic deformity had a wide range of angles, as seen with other causes; nine of the 30 patients had a fixed-type deformity.

Most surgeons favour anterior decompression and fusion because it is familiar and is associated with an acceptable morbidity. It is generally effective in removing 
compressive lesions causing myelopathy. ${ }^{18-20}$ However, there is a mechanical disadvantage in trying to obtain and maintain correction with an anterior approach. ${ }^{5,7}$ There is a high rate of pseudarthrosis, subsidence and dislodgement of the graft in multisegment decompression and fusion involving more than three segments. ${ }^{11-13}$

In our study, the combined anterior and posterior fusion resulted in and maintained a higher degree of correction than did anterior fusion alone. Four patients with an anterior fusion alone had a recurrent kyphotic deformity. O'Shaughnessy et $\mathrm{al}^{5}$ evaluated the mechanism of failure in the anterior approach and found that it places the construct anterior to the axis of rotation of the spine and far anterior to the site of the primary mechanical force, the failure of which leads to kyphosis. This is therefore a mechanically suboptimal strategy which is prone to failure or loss of correction, as any remaining kyphotic alignment increases the load in the anterior plate in flexion, leading to failure of the correction and pseudarthrosis. ${ }^{21}$ Vaccaro et $\mathrm{al}^{22}$ reported a failure of up to $50 \%$ in three-level anterior corpectomy and plate fixation using external halo immobilisation. Sasso et $\mathrm{al}^{12}$ had failure of fixation in $5.5 \%$ of two-level fusions and $83 \%$ of three-level fusions with anterior fusion alone, but none after combined anterior/posterior fusion. Other surgeons have encountered complications with the implants or pseudarthrosis when performing combined anterior and posterior fusion. ${ }^{23,24}$ We had a pseudarthrosis in three of our 15 cases of anterior fusion, but none in the combined procedure. We do not consider that anterior fusion alone is sufficient to obtain optimal correction and prevent pseudarthrosis formation.

Whether to perform the anterior or the posterior approach first depends on the degree of bony ankylosis, the extent of the kyphosis and the presence and location of spinal cord compression. ${ }^{5,6}$ When the deformity is fixed and the posterior elements are ankylosed, a combined approach may be required allowing anterior lengthening and posterior shortening, thereby facilitating reduction of the kyphosis. When the anterior approach is carried out before the posterior for a fixed deformity, it allows an increased angle of correction after the anterior release. However, there is the risk that the anterior interbody grafts may loosen. If the posterior approach is carried out first it enables better assessment of the cervical contour and direct visualisation of the lamina. Therefore, it is better suited for judging any segmental translation which may potentially cause neural injury.

The amount of blood loss and the length of the operation with anterior fusion alone are significantly less than that in the combined procedure. However, we consider that the risk of a longer operation and increased blood loss are acceptable when the improved clinical outcomes and maintenance of correction of the kyphosis are considered. Anterior fusion alone has a higher incidence of complications, and a higher incidence of revision surgery.

Combined anterior and posterior fusion for degenerative cervical kyphotic deformity results in a greater correction of sagittal alignment, a better maintenance of correction angle, a higher rate of fusion, a lower rate of subsidence and lower complications than anterior fusion alone. The combined procedure is more effective, has better outcomes and fewer complications.

\section{Listen live}

Listen to the abstract of this article at www.jbjs.org.uk/interactive/audio

No benefits in any form have been received or will be received from a commercial party related directly or indirectly to the subject of this article.

\section{References}

1. Albert TJ, Vacarro A. Postlaminectomy kyphosis. Spine 1998;23:2738-45

2. Steinmetz MP, Stewart TJ, Kager CD, et al. Cervical deformity correction. Neurosurgery 2007;60(Suppl 1):90-7.

3. Kanter A, Wang MY, Mummaneni PV. A treatment algorithm for the management of cervical spine fractures and deformity in patients with ankylosing spondylitis. Neurosurg Focus 2008;24:E11.

4. Mummaneni PV, Dhall SS, Rodts GE, Haid RW. Circumferential fusion for cervical kyphotic deformity. J Neurosurg Spine 2008;9:515-21.

5. O'Shaughnessy BA, Liu JC, Hsieh PC, et al. Surgical treatment of fixed cervical kyphosis with myelopathy. Spine 2008;33:771-8.

6. Steinmetz MP, Kager CD, Benzel EC. Ventral correction of postsurgical cervical kyphosis. J Neurosurg 2003;98(Suppl 1):1-7.

7. Herman JM, Sonntag VK. Cervical corpectomy and plate fixation for postlaminectomy kyphosis. J Neurosurg 1994;80:963-70.

8. Butler JC, Whitecloud TS 3rd. Postlaminectomy kyphosis: causes and surgical management. Orthop Clin North Am 1992;23:505-11.

9. Anderson DG, Silber JS, Albert TJ. Management of cervical kyphosis caused by surgery, degenerative disease, or trauma. In: Clark CR, ed. The cervical spine. Fourth ed. Philadelphia: Lippincott Williams \& Wilkins, 2005:1135-46.

10. Zdeblick TA, Bohlman H. Cervical kyphosis and myelopathy: treatment by anterior corpectomy and strut-grafting. J Bone Joint Surg [Am] 1989;71-A:170-82.

11. DiAngelo DJ, Foley KT, Vossel KA, Rampersaud YR, Jansen TH. Anterior cervical plating reverses load transfer through multilevel strut-grafts. Spine 2000;25:783-95.

12. Sasso RC, Ruggiero RA Jr, Reilly TM, Hall PV. Early reconstruction failures after multilevel cervical corpectomy. Spine 2003;28:140-2.

13. Zdeblick TA, Hughes SS, Riew KD, BohIman HH. Failed anterior cervical discectomy and arthrodesis: analysis and treatment of thirty-five patients. J Bone Joint Surg [Am] 1997;79-A:523-32.

14. Ganju A, Ondra SL, Shaffrey Cl. Cervical kyphosis. Techniques in Orthopaedics 2003; 17:345-54.

15. Gore DR, Sepic SB, Gardner GM. Roentgenographic findings of the cervical spine in asymptomatic people. Spine 1986;11:521-4.

16. Hilibrand AS, Carlson GD, Palumbo MA, Jones PK, Bohlman HH. Radiculopathy and myelopathy at segments adjacent to the site of a previous anterior cervical arthrodesis. J Bone Joint Surg [Am] 1999;81-A:519-28.

17. Song KJ, Choi BW, Choi BR, Seo GB. Cross-cultural adaptation and validation of the Korean version of the neck disability index. Spine 2010;35:E1045-9.

18. Macdonald RL, Fehlings MG, Tator CH, et al. Multilevel anterior cervical corpectomy and fibular allograft fusion for cervical myelopathy. J Neurosurg 1997;86:990-7.

19. Saunders RL, Bernini PM, Shirreffs TG Jr, Reeves AG. Central corpectomy for cervical spondylotic myelopathy: a consecutive series with long-term follow-up evaluation. J Neurosurg 1991;74:163-70.

20. Bernard TN Jr, Whitecloud TS 3rd. Cervical spondylotoc myelopathy and myeloradiculopathy: anterior decompressio and stabilisation with autogenous fibula strut graft. Clin Orthop 1987;221:149-60.

21. Wang M, Gourab K, McGrady LM, Rao RD. Alteration of load sharing of anterio cervical implants with change in cervical, sagittal alignment. Med Eng Phys 2008; 30:768-73.

22. Vaccaro AR, Falatyn SP, Scuderi GJ, et al. Early failure of long segment anterior cervical plate fixation. J Spinal Disord 1998;11:410-15.

23. Vanichkaehorn JS, Vaccaro AR, Silveri CP, Albert TJ. Anterior junctional plate in the cervical spine. Spine 1998;23:2462-7.

24. Schultz KD Jr, McLaughlin MR, Haid RW Jr, et al. Single-stage anterior-posterior decompression and stabilization for complex cervical spine disorders. J Neurosurg 2000;93(Suppl 2):214-21 